\title{
Effects of flooring and restricted freestall access on behavior and claw health of dairy heifers
}

\author{
W. Ouweltjes, ${ }^{* 1}$ J. T. N. van der Werf, ${ }^{*}$ K. Frankena, $†$ and J. L. van Leeuwen‡ \\ *Wageningen UR Livestock Research, 8200 AB, Lelystad, the Netherlands \\ †Quantitative Veterinary Epidemiology Group, and \\ ‡Experimental Zoology Group, Department of Animal Sciences, Wageningen University, $6700 \mathrm{AH}$, Wageningen, the Netherlands
}

\section{ABSTRACT}

Claw health, locomotion, feed intake, milk yield, body weight, activity, and lying and standing behavior of dairy heifers were monitored in a single dairy herd during the first 3 mo after calving. During the first 8 wk after calving, 2 treatments were applied: restricted freestall access by closing the stalls between $2300 \mathrm{~h}$ and $0500 \mathrm{~h}$ (yes or no) and alley flooring (concrete or rubber topped slatted floors). Apart from treatments, housing was identical. The animals were kept in small groups (n $=4$ to 6 ) in adjacent barn pens. Thereafter, the animals were kept in 1 group in a freestall section with concrete slatted floor and unrestricted access to the stalls for 5 wk. All animals were fed the same partial mixed ration. We hypothesized that (1) hard flooring causes high mechanical load of the claws and (2) restricted freestall access causes prolonged standing bouts and reinforced effects of hard flooring on claws. The heifers had only minor claw lesions before first calving, and the prevalence and severity of sole hemorrhages increased during the first 3 mo after calving (from $0.24 \pm 0.08$ to $1.18 \pm$ 0.14 and from $0.04 \pm 0.01$ to $0.24 \pm 0.02$, respectively), particularly in the outer hind claws. Animals kept on rubber alley flooring had lower average hemorrhage scores in wk $9(0.13 \pm 0.03$ vs. $0.21 \pm 0.03)$ and wk 14 $(0.20 \pm 0.03$ vs. $0.27 \pm 0.03)$ after calving, had a slower feed intake $(3.05 \pm 0.14 \mathrm{vs} .3 .46 \pm 0.14 \mathrm{~g} / \mathrm{s})$ and spent more time feeding $(7.3 \pm 0.3$ vs. $6.6 \pm 0.3 \mathrm{~min} / \mathrm{h})$ than animals kept on hard concrete alley floors. Restricted freestall access resulted in fewer standing bouts per day $(14.4 \pm 1.0$ vs. $17.9 \pm 1.0)$ and more strides per hour $(99.8 \pm 5.4$ vs. $87.2 \pm 5.4)$ without changing overall standing time $(15.0 \pm 0.3$ vs. $14.7 \pm 0.3 \mathrm{~h} / \mathrm{d})$ and did not affect the occurrence of sole hemorrhages. The animals with no overnight freestall access spent more time standing $(55.9 \pm 0.9$ vs. $35.8 \pm 0.9 \mathrm{~min} / \mathrm{h})$ and feeding $(7.8 \pm 0.3$ vs. $4.3 \pm 0.3 \mathrm{~min} / \mathrm{h}$ ) between 2300

Received February 26, 2010.

Accepted November 4, 2010.

${ }^{1}$ Corresponding author: Wijbrand.Ouweltjes@wur.nl and $0500 \mathrm{~h}$ and less during the rest of the 24-h period $(31.3 \pm 0.8$ vs. $37.0 \pm 0.8 \mathrm{~min} / \mathrm{h}$ and $6.8 \pm 0.3$ vs. 7.6 $\pm 0.3 \mathrm{~min} / \mathrm{h}$ ). Thus, the animals adapted to restricted freestall access, that caused increased overnight standing, by additional lying down during the day and used part of the extra standing time at night for feeding. The restrictions probably had only a minor effect on the mechanical load of their claws. Therefore, the first part of the hypothesis was confirmed and the second part was rejected.

Key words: alley floor, claw health, lying and standing behavior, restricted freestall access

\section{INTRODUCTION}

Several studies reported that claw lesions and locomotive problems are widespread among dairy cattle (Somers, 2004; Holzhauer, 2006), especially in freestall herds (Sogstad et al., 2005a). Claw disorders in dairy cows probably cause pain and are the main cause for impaired mobility in an environment that requires cows to move around for resources. Sole hemorrhages, indicating tissue damage inside the claw, are often detected in the claws of Dutch dairy cattle (Holzhauer, 2006).

The etiology of hemorrhages is complex and is traditionally linked to metabolic factors, but it is hypothesized that mechanical overload of the claws is a main cause of sole hemorrhages (SH; Logue et al., 2004). Yet, mechanical load is not easily quantifiable under practical circumstances. Galindo et al. (2000) argue that social and individual behavior affect individual susceptibility to present foot lesions under the same environment. Epidemiological research has shown that heifers experience higher incidences of SH than older cows (Donovan et al., 2004; Sogstad and Østerås, 2005b), and that the occurrence of SH increases after parturition (Le Fevre et al., 2001; Tarlton et al., 2002). This suggests that sensitivity for overload not only differs between animals, but varies in time for each animal.

Approximately $80 \%$ of Dutch dairy cows are housed in freestall barns, of which more than $90 \%$ are equipped with slatted concrete floors (Somers, 2004). Such floors 
are associated with suboptimal locomotion. Several investigations reported beneficial effects on locomotion when concrete floors were equipped with rubber walking surfaces (Rushen and de Passilé, 2006; Flower et al., 2007; Telezhenko, 2007), and there is growing interest among farmers to apply rubber top layers in their barns. Ouweltjes et al. (2009) reported a lower prevalence of $\mathrm{SH}$, but more standing and walking on a rubber-topped slatted floor vs. a concrete slatted floor. Kremer et al. (2007) reported similar results. Tucker et al. (2006) showed that cows preferred compliant surfaces (sawdust or Animat rubber) in front of the feed bunk over hard concrete floors, and Telezhenko (2007) reported a preference of cows for compliant flooring both for standing and walking.

Although rubber-topped alley floors decrease the environmental challenge for mechanical overload compared with concrete floors, Kremer et al. (2007) and Vanegas et al. (2006) reported that such flooring did not significantly reduce the overall incidence of claw disorders. In contrast, Somers (2004) reported substantially lower incidences of claw lesions for cows kept in straw pens vs. freestall barns. Straw pens are not only characterized by compliant flooring in the bedding area, but also provide the animals freedom to lie down and get up. This could affect their lying and standing behavior. Leonard et al. (1996) concluded that reduced lying time exacerbated the development of claw lesions. Correspondingly, Cook and Nordlund (2009) stressed the importance of sufficient resting time for claw health. These studies suggest that prolonged standing has negative effects on claw tissues that can be compensated for by lying bouts of sufficient length. Positive effects of straw pens on claw health could be due to changes in time budgets. Changes in alteration of lying and standing could affect claw health, even with fixed overall time budgets.

The effect of the interaction of floor hardness and lying and standing behavior on the overall risk of overloading claws is currently unknown. This hampers tailored prevention of overload in practice. Moreover, timely detection of overload is not yet possible because good early warning signals are lacking. Hemorrhages become visible in the sole horn around 2 mo after the tissue is actually damaged and are currently the best measure for overload, but their occurrence is not solely attributable to overload. Often animals with hemorrhages are not visibly lame, but tissue damage causing the hemorrhages may lead to discomfort and could affect behavior. This hypothesis can be investigated with motion sensors such as IceTags (IceRobotics, Ltd., Roslin, UK) and feed intake recordings (RIC) that enable more or less continuous recording of behavioral measures.
The aim was to quantify effects of housing conditions that could affect mechanical load on behavior and the development of SH in heifers after first calving. We hypothesized (1) that hard concrete flooring causes high mechanical load on the claws (relative to more compliant rubber flooring), and (2) that restricted freestall access causes prolonged standing bouts and reinforces effects of hard flooring on claws. Both factors will increase the occurrence of $\mathrm{SH}$, and effects will be visible within 3 mo after calving.

\section{MATERIALS AND METHODS}

\section{Animals and Housing Conditions}

The study was carried out at the De Waiboerhoeve research farm of the Animal Sciences Group (current name: Wageningen UR Livestock Research) in Lelystad, the Netherlands. Criteria for inclusion of heifers were as follows: normal development, clinically healthy (as determined by visual observation), calved within 2 wk of expected calving date, no history of difficult calving or a retained placenta, and had a locomotion score of 2 or less on the 5 -point scale (Manson and Leaver, 1988). All 44 Holstein heifers used were raised on a contract farm, where they were kept in freestalls with concrete alley floors and returned to the research farm approximately $5 \mathrm{wk}$ before the expected calving date. From then on, they were kept in a straw pen (together with cows in the close-up period). This comprised the pretreatment period. The day after calving, the heifers entered the experiment: treatments were allotted in blocks of 4, and consisted of a combination of floor and restricted stall access (see treatments) in a freestall barn with slatted alley floors. Besides the freestalls, the animals had approximately $20 \mathrm{~m}^{2}$ of alley space available per treatment group of 6 animals.

All animals were kept in their treatment environment for $8 \mathrm{wk}$ (treatment period) and kept in a barn pen with a concrete slatted floor with unrestricted access to the freestalls during wk 9 to 13 of the experiment (posttreatment period). Group size during the treatment phase was a minimum of 4 animals, with maximum size of treatment groups of 6 animals. If needed, fill animals (heifers only) were added to the groups. During the posttreatment period, group size varied between 6 and 17. Throughout the experiment 1 stall was available per animal.

The same partially mixed ration (PMR) was available ad libitum in the RIC feeding troughs (Insentec, Marknesse, the Netherlands) for all treatments; ration formulation was according to Dutch nutritional guidelines. Feeders were emptied and refilled once daily; for each treatment, a minimum of 1 feeder was available per 
Table 1. Measurement scheme for all variables

\begin{tabular}{|c|c|c|c|c|c|c|c|c|c|c|c|c|c|c|}
\hline Measurement & \multicolumn{14}{|c|}{ Experimental week $^{1}$} \\
\hline Claw health & $\mathrm{v}$ & & & & & & & & $\mathrm{v}$ & & & & & $\mathrm{v}$ \\
\hline Locomotion & $\mathrm{V}$ & $\mathrm{v}$ & $\mathrm{v}$ & $\mathrm{v}$ & $\mathrm{v}$ & $\mathrm{v}$ & $\mathrm{v}$ & $\mathrm{v}$ & $\mathrm{v}$ & $\mathrm{v}$ & $\mathrm{v}$ & $\mathrm{v}$ & $\mathrm{v}$ & \\
\hline Feed intake & $\mathrm{x}$ & $\mathrm{x}$ & $\mathrm{x}$ & $\mathrm{x}$ & $\mathrm{x}$ & $\mathrm{x}$ & $\mathrm{x}$ & $\mathrm{x}$ & $\mathrm{x}$ & $\mathrm{x}$ & $\mathrm{x}$ & $\mathrm{x}$ & $\mathrm{x}$ & \\
\hline Milk production & $\mathrm{m}$ & $\mathrm{m}$ & $\mathrm{m}$ & $\mathrm{m}$ & $\mathrm{m}$ & $\mathrm{m}$ & $\mathrm{m}$ & $\mathrm{m}$ & $\mathrm{m}$ & $\mathrm{m}$ & $\mathrm{m}$ & $\mathrm{m}$ & $\mathrm{m}$ & \\
\hline
\end{tabular}

${ }^{1} \mathrm{v}=1$ visual observation per animal per week, $\mathrm{x}=$ continuous automated recording, $\mathrm{m}=$ daily automated recording per milking.

2 cows. The ration consisted of soy hulls (3.4\%), mineral mixture $(0.1 \%)$, salt $(0.1 \%)$, concentrate $(12.9 \%)$, corn silage $(43.3 \%)$, and grass silage $(40.0 \%)$, and had $43.4 \%$ DM. The cows were milked twice daily in a conventional parlor and received 1 to $4 \mathrm{~kg}$ of concentrate daily during milking, depending on their production level and day in lactation. Floors between the treatment compartments and the parlor were slatted concrete. Every $2 \mathrm{wk}$, a footbath with a solution of formalin or formalin-copper sulfate, was alternately placed in their path for $2 \mathrm{~d}$. The study was approved by the institute's Animal Care and Ethics Committee. The animals entered the study between November 28, 2008, and March 28, 2009.

\section{Treatments}

Four treatments were applied in adjacent barn compartments separated with metal bars: concrete floor and restricted freestall access, concrete floor and unrestricted access to the freestalls, rubber-topped floor and restricted access to the freestalls, and rubbertopped floor and unrestricted access to the freestalls. Restricted freestall access was achieved by locking the stalls with a metal bar between 2300 and 0500 h. From wk 9 to 13, the animals were kept on concrete floors with unrestricted access to the freestalls. Two of the freestall sections used for the experiment had a slatted concrete floor covered with rubber (Kraiburg KuraS, Tittmoning, Germany); the other freestall sections had an identical slatted concrete floor without rubber top layer. The prefabricated concrete floors were provided by Concrelit Betonindustrie (Steenwijk, the Netherlands). The floors were cleaned with a robotic manure scraper (Lely Industries, Maassluis, the Netherlands).

\section{Measurements}

The cows were monitored for claw health, time spent lying, standing, or active (with IceTags), locomotion, feed intake, milk production, and BW. Measurement frequencies varied per variable (Table 1 ).
The occurrence of claw disorders was recorded for each inner and outer claw of the front and hind legs by scoring the presence of $\mathrm{SH}$, sole ulcers, digital dermatitis, interdigital dermatitis (ID), tyloma (also known as interdigital hyperplasia), and interdigital phlegmon according to Holzhauer (2006). The SH were scored for 6 different regions on a scale of 1 (mild) to 5 (severe) according to Leach et al. (1998; Figure 1). If present, digital dermatitis and ID were scored on a scale from 1 (mild) to 3 (severe) according to the judgment of the observer; the other disorders were scored as either present (1) or absent (0). Prior to the observations, claws were cleaned and a small amount of sole horn was removed to enable scoring of horn lesions. The claws were scored in wk 1, 9, and 14 after calving.

From at least $1 \mathrm{wk}$ before calving onward, the animals were equipped with IceTag activity sensors (v. 2.004 and 3.001, IceRobotics Ltd.). The sensors sampled acceleration data with 8 and $16 \mathrm{~Hz}$, respectively, and onboard software reported the percentage of time the animal was lying, standing, or active and the number of strides of the leg to which the sensor was attached with a sampling rate of $1 \mathrm{~Hz}$. The term "stride" was adopted from McNeill Alexander (2003), who defines a stride as a complete cycle of a foot movement. Locomotion variables were scored weekly when the animals walked back to their pen along a straight alley with a concrete slatted floor after they were locked in a feeding headlock to read the IceTags. Traits observed were locomotion score (according to the method of Manson and Leaver, 1988) and the duration and number of strides with both hind legs needed to travel $10.36 \mathrm{~m}$ of the alley floor. Feed intake and each individual visit to a feeder were recorded with the automated RIC system. Milk yield was recorded in the parlor with International Committee for Animal Recording-approved equipment. Body weights were measured with a scale before entering the parlor. During the experiment, equipment performance was monitored according to standard farm procedures. 


\section{Data Processing}

IceTag data were preprocessed before statistical analysis. IceTag data were disregarded on days when claw condition or locomotive performances were visually scored because cows were disturbed by these interventions. Similarly, data from the day the animals went from the treatment to posttreatment group were excluded because data from those days may not have been representative. Remaining data per second were redefined to represent either lying (when percentage of time spent lying was $\geq 50$ ) or standing. Then the data were aggregated per minute. Variables calculated were number of seconds with records, number of seconds recorded as standing, and number of strides. These data were aggregated further per hour and per day. From the data aggregated per minute, standing bouts were derived. First, data per minute were classified as lying or standing. Second, standing bouts were defined to start at the first minute classified as standing after at least $1 \mathrm{~min}$ classified as lying and were said to end when the next minute was classified as lying. Finally, the number of standing bouts starting in each hourly period was counted. Separate data sets were made for the precalving period, treatment period, and posttreatment period. For each experimental phase, 3 traits were analyzed: percentage of time spent standing, number of strides, and number of standing bouts.

Feeding data were processed before creating data sets for analysis; $2.7 \%$ of the records of feeding visits were marked as unreliable and removed from the data set. Data for which calculated individual daily intake was $<10 \mathrm{~kg}$ of roughage/d, or where calculated daily intake deviated more than 3 units of standard deviation from the trend calculated for the animal (with third-order polynomials) were discarded. After these edits, 1,901 daily intakes for the treatment period and 1,025 daily intakes for the posttreatment period could be calculated. From the available data, the following traits were derived: feeding time, feed intake, number of meals, and intake speed. For further analysis, data were aggregated per hour and per day.

For each milking, the length of the preceding interval was calculated in minutes by subtracting the milking time of the preceding milking from the current milking time. Milk yields were recalculated in grams per hour of the preceding interval, and then trends per animal were fitted with third-order polynomials. Productions that deviated more than 2 units of standard deviation from the trend were removed from the data set. A similar filter was applied to BW data. Smaller deviations (2 units instead of 3 ) from the calculated trends were accepted for milk yield and BW compared with feed

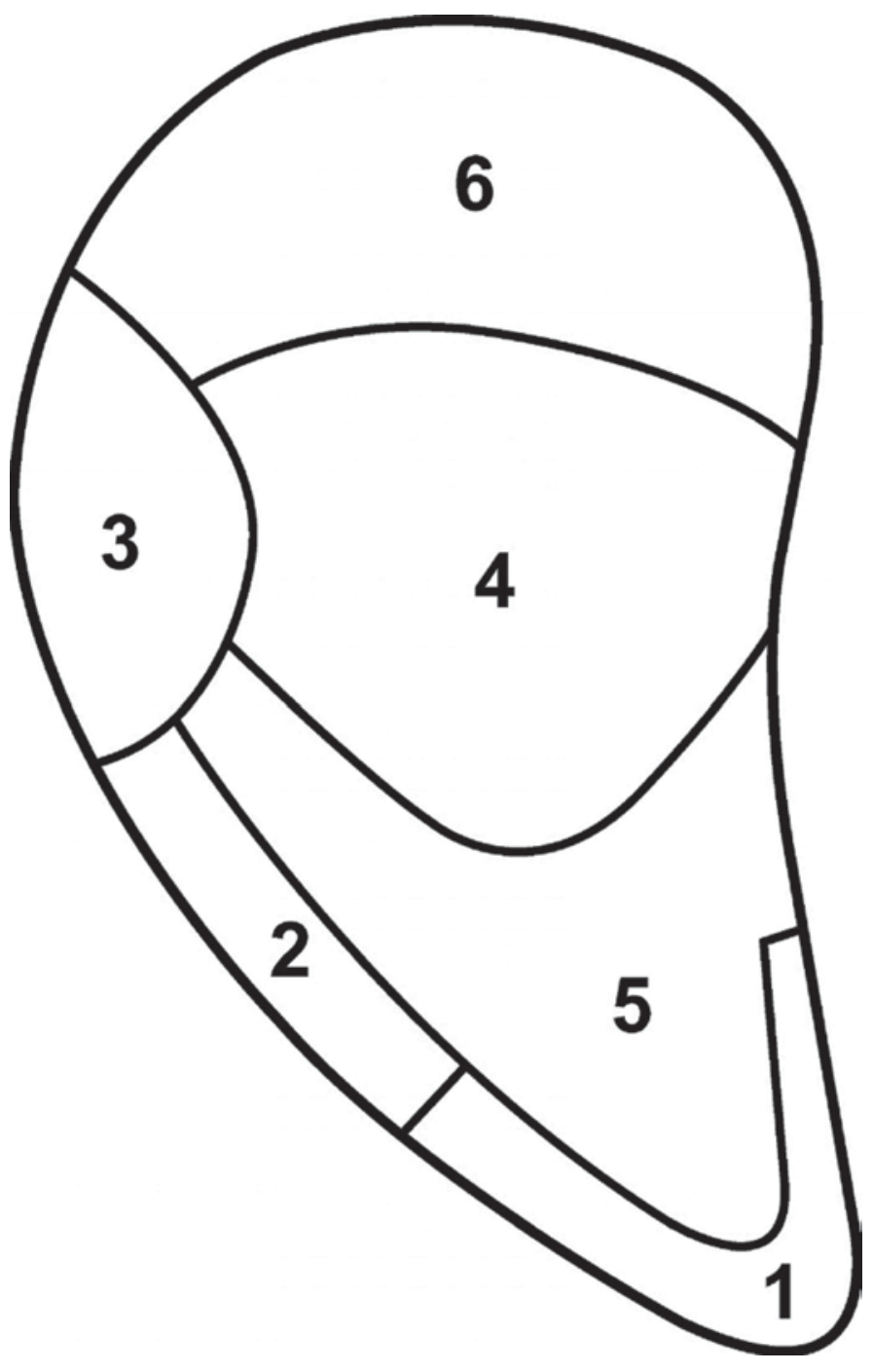

Figure 1. Claw zones separately scored for each claw (Leach et al., 1998).

intake because it was assumed that these were more likely to be due to recording errors.

\section{Statistical Procedure}

Claw disorders were analyzed with ASReml statistical package with the following general linear mixed model (where $\times$ represents main effects and interactions):

$$
\begin{aligned}
Y_{i j k l m n o}=\mu & +F_{i} \times L r_{j}+L g_{k} \times C_{l}+B l_{m} \\
& +A n_{m n}+e_{i j k l m n o},
\end{aligned}
$$

where $Y_{i j k l m n o}$ is the variable recorded for floor $i$, restricted freestall access $j$, leg $k$, claw $l$, block of entry $m$, and cow $n$ within block $m$, and repeated observa- 
tion $o ; \mu$ is the overall mean, $F_{i}$ is the type of floor on which a cow was kept (concrete, rubber), $L r_{j}$ represents restricted freestall access (yes, no), $L g_{k}$ represents leg, $C_{l}$ is claw (inner or outer), $B l_{m}$ represents the block of entry $(m=1,11), A n_{m n}$ is the individual animal effect $(l=1,44)$, and $e_{i j k l m n o}$ is the error term; $B l_{m}, A n_{m n}$, and $e_{i j k l m n o}$ are the random components of the model. Digital dermatitis, ID, and sole ulcers were seldom diagnosed: digital dermatitis was scored for 2, 1 , and 4 legs when the animals entered the experiment and 8 and $13 \mathrm{wk}$ later, respectively; ID was scored for 3, 1 and 1 legs, and sole ulcer was only scored once in wk 14 . Therefore, only data for SH were statistically analyzed. Traits analyzed were number of zones with SH (num_sh) for each inner or outer claw and average score for $\mathrm{SH}$ in zones 1 to 6 (score_sh). A zone effect was added to model [1] for the analysis of SH per zone. Data were analyzed separately for measurements in wk 1, 9, and 14 .

Locomotion, IceTag data, feed intake, milk yield, and BW were analyzed with the ASReml statistical package with the following general linear mixed model (where $x$ represents main effects and interactions and - represents interactions only):

$$
\begin{gathered}
Y_{i j k l m n o p}=\mu+F_{i} \times L r_{j}+F_{i} \cdot L r_{j} \cdot L w_{k}+F_{i} \cdot L r_{j} \\
D p_{l}+B l_{m}+A n_{m n}+\operatorname{spl}\left(W k_{o}\right)+e_{i j k l m n o p}
\end{gathered}
$$

where $Y_{i j k l m n o p}$ is the variable recorded for floor $i$, restricted freestall access $j$, stage of lactation $k$, period $l$ within day, block of entry $m$, animal $n$ within block $m$, and day or week $o$ during the experiment and repeated observation $p ; \mu$ is the overall mean; $F_{i}$ is the type of floor on which a cow was kept during the treatment period (concrete, rubber); $L r_{j}$ represents restricted freestall access (yes, no); $L w_{k}$ represents week or day of lactation; $D p_{l}$ represents diurnal effects of hour period or morning versus afternoon; $B l_{m}$ represents the block of entry $(m=1,11) ; A n_{m n}$ is the individual animal effect $(l=1,44) ; \operatorname{spl}\left(W k_{o}\right)$ represents daily or weekly environmental fluctuations throughout the experiment; and $e_{i j k l m n o p}$ is the error term. $B l_{m}, A n_{n}, \operatorname{spl}\left(W k_{o}\right)$, and $e_{i j k l m n o p}$ are the random components of the model. Most variables were corrected for effects of day in lactation within treatment, but locomotion traits (scored once per week) were corrected for lactation weeks within treatment. IceTag data and feed intake data were corrected for hour within day, and milk yield and BW were corrected for differences between morning and afternoon. Locomotion variables were not corrected for diurnal effects because these were observed once per week. Furthermore, IceTag data were corrected for sensor type $(2 \mathrm{D}$ or $3 \mathrm{D})$, and feed intake data were cor- rected for feeder effects. These variables were added as random variables. For all variables, effects were tested against variation between animals within treatments.

\section{RESULTS}

\section{General}

One animal was removed from the trial 3 wk after calving and replaced because it lay down in the alley too often during the restriction period. This animal did not have visible health problems and the data from this animal were excluded from the analysis. The other animals resigned to the lying restriction and mainly kept standing during this period, although occasionally animals were seen lying on the alley floor. One animal from the rubber-topped floor and unrestricted access to the freestalls treatment could not be kept in the experiment until 3 mo after calving because it became seriously ill 10 wk after calving and was transferred to the straw-covered pen. The illness was not due to claw or leg disorders, and the data from this animal until she became ill are included in the analysis.

\section{Behavior Recorded with IceTags}

Results regarding treatment effects were similar for the data aggregated per hour and per day, and because the analysis per hour provides more information, results presented are from the analysis of data aggregated per hour. Predicted means and significance levels of the fixed effects in the model for each experimental phase are given in Table 2 .

The figures in Table 2 indicate that the percentage of time spent standing was increased in the treatment period compared with the precalving and posttreatment periods. For number of strides per hour, a similar increase occurred after calving in the treatment period, but the number of strides in the posttreatment period remained higher than precalving. The number of bouts per hour increased over time. Treatment groups did not differ for percentage of time spent standing, number of bouts or number of strides per hour before calving. During the treatment period, the animals with restricted freestall access had significantly more strides per hour and less standing bouts per hour than the unrestricted animals. These differences disappeared in the posttreatment period. The overall percentage of time spent standing was not affected. The predicted means $( \pm \mathrm{SE})$ for restricted and unrestricted groups in each experimental phase for all 3 traits are presented in Figure 2. To obtain more comparable scales, the number of standing bouts was expressed per day. Figure 2 illustrates that lying restricted animals made more strides per hour $(99.8 \pm 5.4$ 


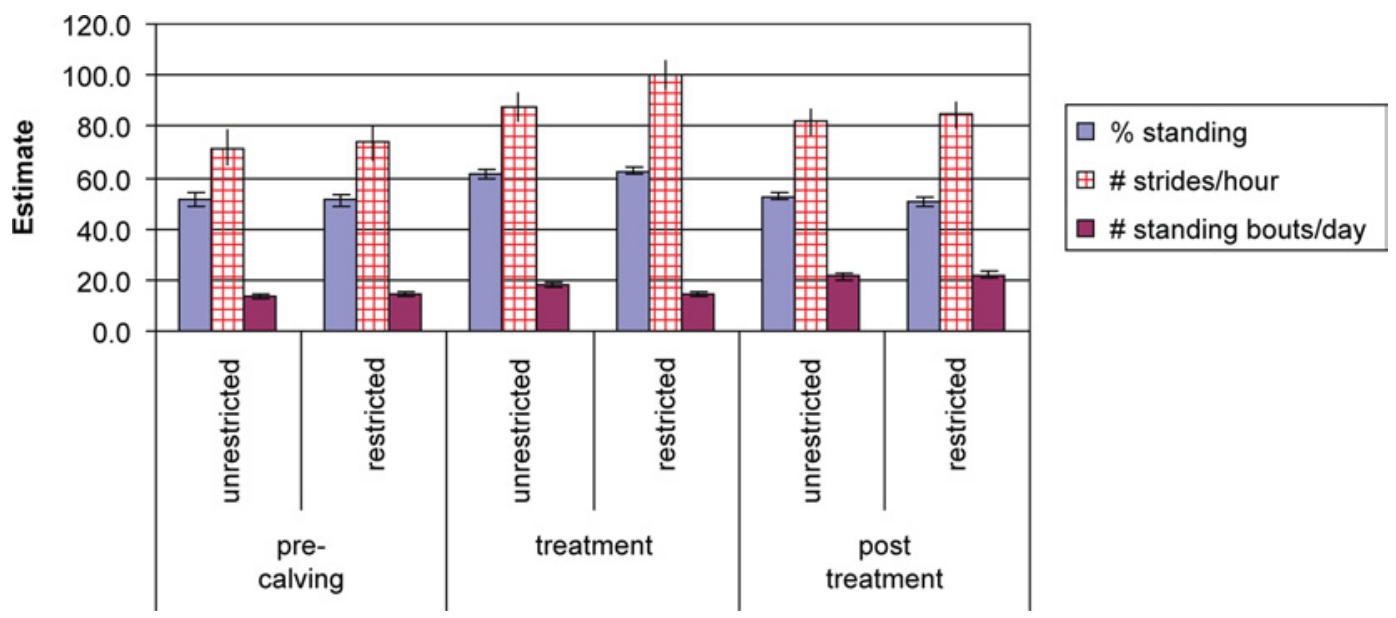

Figure 2. Predicted means $( \pm \mathrm{SE})$ of restricted and unrestricted groups for percentage of time spent standing, number of strides per hour, and number of standing bouts per day for each experimental phase. Color version available in the online PDF.

vs. $87.2 \pm 5.4)$ and had fewer standing bouts per day $(14.4 \pm 1.0$ vs. $17.9 \pm 1.0)$ during the treatment period than the unrestricted animals.

For all traits, significant effects of $F \times L r \times L w$ and $F \times L r \times D p$ were found. The effect of $F \times L r \times L w$ reflected that trait levels were not constant over time. Differences between the treatment groups in development of the levels over time were not substantial (Figure 3). Particularly around calving, the percentage of time spent standing and the number of strides per hour were increased, but returned to more moderate levels within a few days after calving. The number of standing bouts was low the first days after calving for all treatment groups. The effect of $F \times L r \times D p$ reflected 2 phenomena: (1) lying and standing were not evenly distributed over the 24-h period and (2) despite the absence of overall effects of restricted freestall access on the percentage of time spent standing, this treatment factor did affect diurnal patterns of lying and standing. This is illustrated in Figure 4. Patterns for percentage of time spent standing and number of strides per hour were quite similar, but the number of standing bouts showed a reverse pattern. Prior to calving, the animals were lying most of the time at night. During the treatment period, the animals that had no overnight access to the freestalls were standing most of the time at night, and the unrestricted animals stood more at night than before calving and post treatment. The restricted animals compensated by lying during the day and after the afternoon milking. Peaks of activity in early morning and afternoon indicate milkings. Posttreatment differences between treatment groups had disappeared, but nighttime activity remained higher than precalving.

Table 2. Predicted means for percentage of time spent standing, number of strides per hour, and number of standing bouts per hour (IceTag data), and $P$-values for model terms

\begin{tabular}{|c|c|c|c|c|c|c|}
\hline \multirow[b]{2}{*}{ Item } & \multirow[b]{2}{*}{ Mean \pm SE } & \multicolumn{5}{|c|}{ Model term ${ }^{1}$} \\
\hline & & $F$ & $L r$ & $F \times L r$ & $F \times L r \times L w$ & $F \times L r \times D p$ \\
\hline Precalving & $51.3 \pm 2.5$ & 0.978 & 0.508 & 0.259 & $<0.001$ & $<0.001$ \\
\hline Treatment & $61.9 \pm 1.3$ & 0.166 & 0.271 & 0.305 & $<0.001$ & $<0.001$ \\
\hline Posttreatment & $51.7 \pm 1.4$ & 0.055 & 0.269 & 0.856 & $<0.001$ & $<0.001$ \\
\hline \multicolumn{7}{|c|}{ Number of strides per hour } \\
\hline Posttreatment & $83.2 \pm 4.1$ & 0.508 & 0.569 & 0.985 & $<0.001$ & $<0.001$ \\
\hline \multicolumn{7}{|c|}{ Number of standing bouts per hour } \\
\hline Precalving & $0.58 \pm 0.04$ & 0.301 & 0.508 & 0.651 & 0.001 & $<0.001$ \\
\hline Treatment & $0.67 \pm 0.03$ & 0.489 & 0.020 & 0.311 & $<0.001$ & $<0.001$ \\
\hline Posttreatment & $0.91 \pm 0.04$ & 0.429 & 0.784 & 0.482 & 0.023 & $<0.001$ \\
\hline
\end{tabular}

${ }^{1} F=$ flooring, $L r=$ restricted freestall access, $L w=$ lactation stage (d), and $D p=$ hour period. 

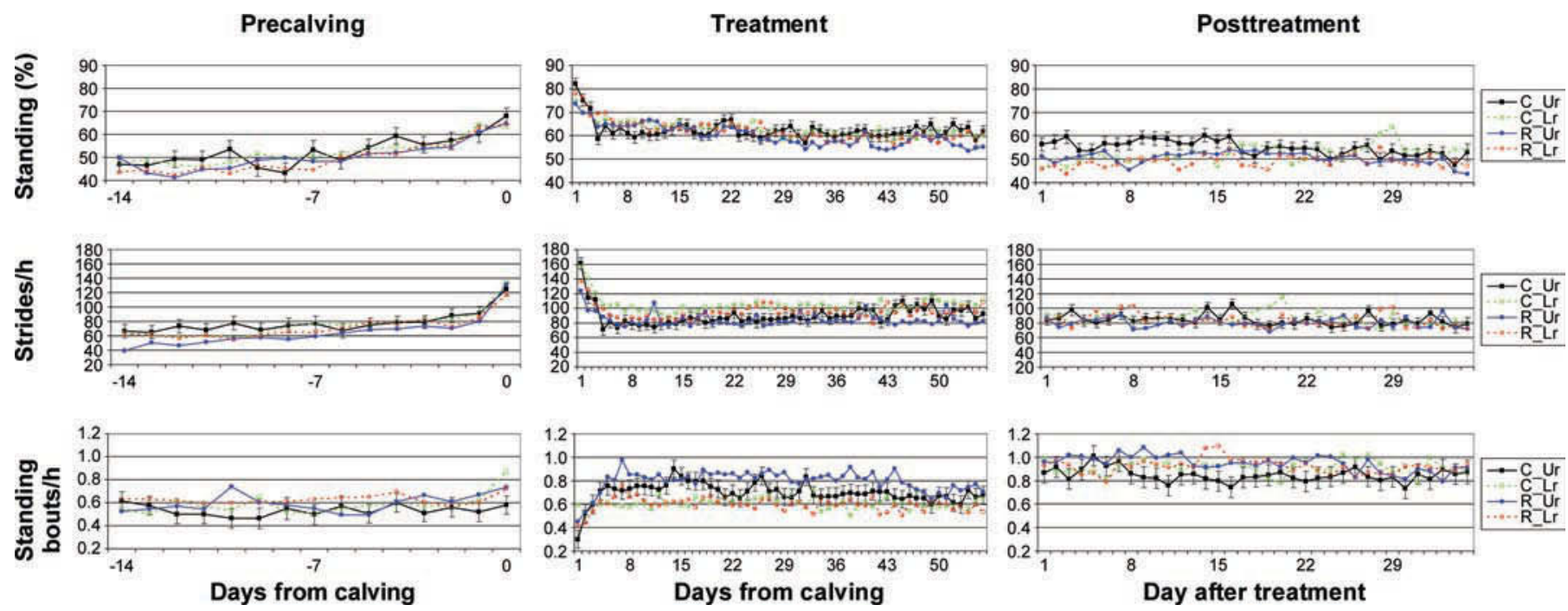

Figure 3. Model predictions $( \pm \mathrm{SE})$ for each experimental group for average percentage of time spent standing, number of strides per hour, and number of standing bouts per hour per day for each experimental phase [model term $F \times L r \times L w$ in model [2]; $F=$ flooring, $L r=$ restricted freestall access, $L w=$ lactation stage (d)]. Magnitudes of SE are similar for all groups; to improve readability, SE is only presented for the group kept on concrete floors with unrestricted access to the freestalls. $\mathrm{C}=$ concrete floor; $\mathrm{R}=$ rubber-topped floor; Ur $=$ unrestricted access to the freestalls; $\mathrm{Lr}=$ restricted acccess to the freestalls. Color version available in the online PDF.

\section{Feed Intake}

During the treatment period, the average PMR intake was $30.6 \pm 0.6 \mathrm{~kg}$ /animal per day $(12.1 \pm 0.3$ $\mathrm{kg}$ of DM); during the posttreatment period, the average PMR intake was $36.0 \pm 0.6 \mathrm{~kg}$ /animal per day $(16.4 \pm 0.3 \mathrm{~kg}$ of $\mathrm{DM})$. Results regarding treatment effects were similar for the data aggregated per hour and per day. Because the analysis per hour provides more information, results refer to data aggregated per hour. Predicted means and significance levels of the fixed effects in the model for each experimental phase are given in Table 3 .

Data in Table 3 show that flooring was related to time spent feeding and intake speed during the treatment period, but other than that, no differences be-
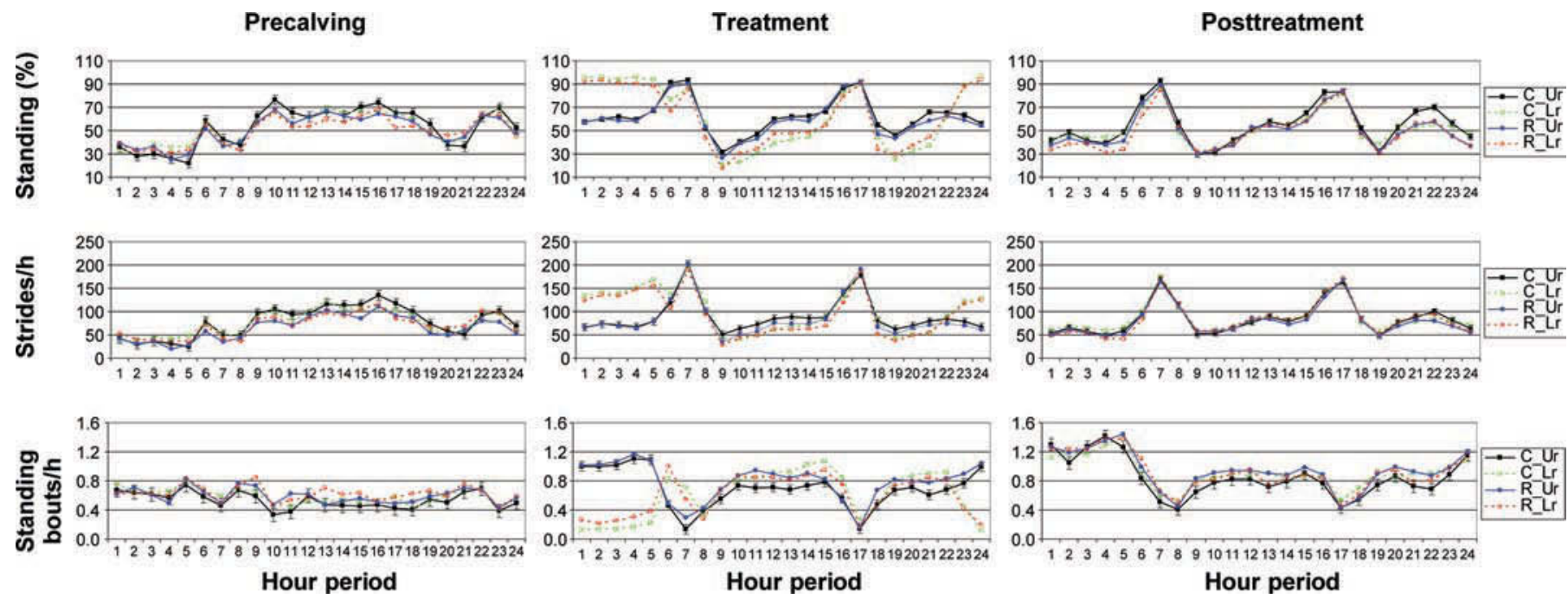

Figure 4. Model predictions $( \pm \mathrm{SE})$ for each experimental group for average percentage of time spent standing, number of strides, and number of standing bouts per hour period for each experimental phase (model term $F \times L r \times D p$ in model [2]; $F=$ flooring; $L r=$ restricted freestall access; $D p=$ hour period). Magnitudes of SE are similar for all groups; to improve readability, SE is only presented for the group kept on concrete floors with unrestricted access to the freestalls. $\mathrm{C}=$ concrete floor; $\mathrm{R}=$ rubber-topped floor; $\mathrm{Ur}=$ unrestricted access to the freestalls; Lr $=$ restricted acccess to the freestalls. Color version available in the online PDF. 

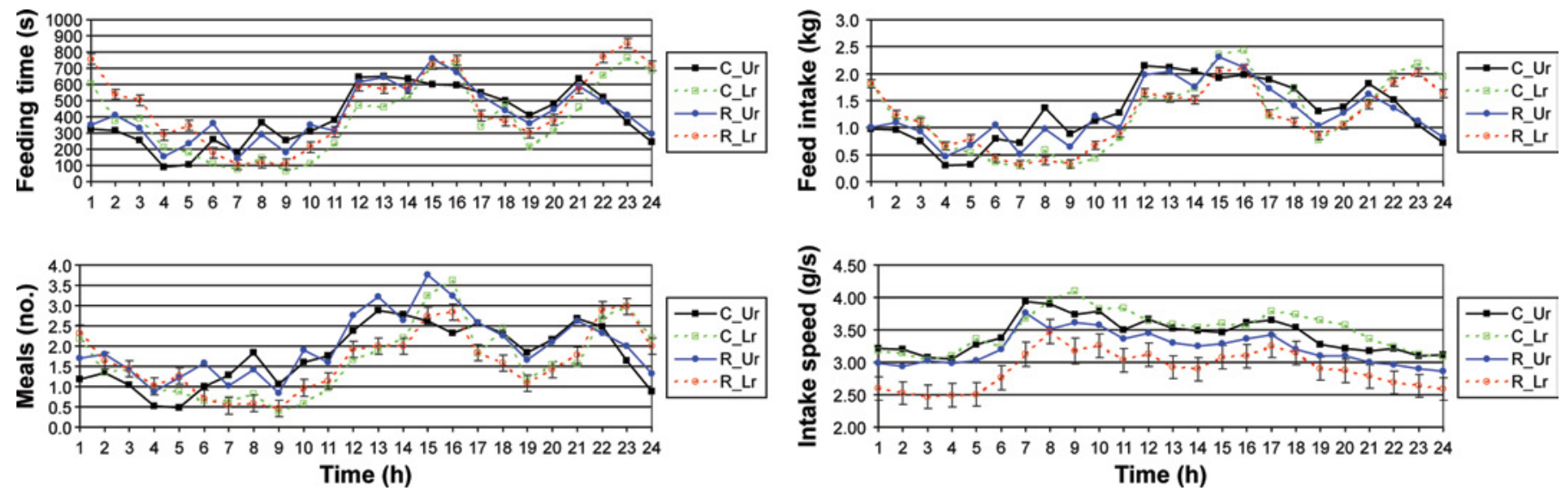

Figure 5. Model predictions $( \pm \mathrm{SE})$ for each experimental group for average feeding time, feed intake, number of meals, and intake speed per hour period during the treatment phase (model term $F \times L r \times D p$ in model [2]; $F=$ flooring; $L r=$ restricted freestall access; $D p=$ hour period). Magnitudes of SE are similar for all groups: to improve readability, SE is only presented for group on concrete floors with unrestricted access to the freestalls. $\mathrm{C}=$ concrete floor; $\mathrm{R}=$ rubber-topped floor; $\mathrm{Ur}=$ unrestricted access to the freestalls; $\mathrm{Lr}=$ restricted access to the freestalls. Color version available in the online PDF.

tween the treatment groups were found. The animals on the rubber floor spent more time feeding $(7.3 \pm 0.3$ vs. $6.6 \pm 0.3 \mathrm{~min} / \mathrm{h})$ and ate more slowly $(3.05 \pm 0.14$ vs. $3.46 \pm 0.14 \mathrm{~g} / \mathrm{s}$ ) than the animals on the concrete floor. The estimates for $F \times L r \times L w$ revealed the same pattern for all experimental groups and showed a gradual increase in feeding time and feed intake during the treatment period. The estimates for $F \times L r \times D p$ during the treatment period in Figure 5 show diurnal patterns that were different for the animals with restricted and unrestricted freestall access. The animals that had no overnight freestall access spent more time feeding at night. Patterns for feeding time, number of meals, and feed intake were similar, but feed intake speed was higher during the day than at night. In the posttreatment period, the diurnal patterns of feed intake for all treatment groups were similar to those for the unrestricted groups in the treatment period.

\section{Claw Disorders}

Figures for num_sh represent the number of claw zones with hemorrhages per claw half (maximum theoretically is 6) and figures for score_sh represent the average hemorrhage score per zone for each inner or outer claw (scored on a scale from 0 to 5 ). Predicted means and significance levels of the fixed effects in the model are given in Table 4.

Table 4 indicates that no significant differences were found in claw health between groups at the start of the treatments. The prevalence of hemorrhaged zones increased during the first 3 mo after calving. Significantly more hemorrhaged zones were found in hind legs than in fore legs for all measurements. In hind legs, most hemorrhages occurred in outer claws; in fore legs, most hemorrhages occurred in inner claws, but the interaction was not significant for num_sh in wk 1, probably

Table 3. Predicted means for feeding time, feed intake, and number of meals, and $P$-values for model terms

\begin{tabular}{|c|c|c|c|c|c|c|}
\hline \multirow[b]{2}{*}{ Item } & \multirow[b]{2}{*}{ Mean $\pm \mathrm{SE}$} & \multicolumn{5}{|c|}{ Model term ${ }^{1}$} \\
\hline & & $F$ & $L r$ & $F \times L r$ & $F \times L r \times L w$ & $F \times L r \times D p$ \\
\hline Treatment & $6.9 \pm 0.2$ & 0.040 & 0.420 & 0.167 & $<0.001$ & $<0.001$ \\
\hline Posttreatment & $8.1 \pm 0.3$ & 0.314 & 0.932 & 0.180 & 1.000 & $<0.001$ \\
\hline \multicolumn{7}{|l|}{ Feed intake, kg/h } \\
\hline Treatment & $1.25 \pm 0.02$ & 0.356 & 0.198 & 0.897 & $<0.001$ & $<0.001$ \\
\hline Treatment & $1.75 \pm 0.09$ & 0.551 & 0.181 & 0.495 & $<0.001$ & $<0.001$ \\
\hline Posttreatment & $1.46 \pm 0.11$ & 0.389 & 0.314 & 0.970 & 0.973 & $<0.001$ \\
\hline \multicolumn{7}{|l|}{ Intake speed, $\mathrm{g} / \mathrm{s}$} \\
\hline Treatment & $3.28 \pm 0.12$ & 0.010 & 0.197 & 0.263 & $<0.001$ & $<0.001$ \\
\hline Posttreatment & $3.13 \pm 0.12$ & 0.184 & 0.895 & 0.331 & $<0.001$ & $<0.001$ \\
\hline
\end{tabular}

${ }^{1} F=$ flooring, $L r=$ restricted freestall access, $L w=$ lactation stage (d), and $D p=$ hour period. 
Table 4. Predicted means for number of sole hemorrhages (Num_sh) and hemorrhage score per zone (Score_sh), and $P$-values for model terms

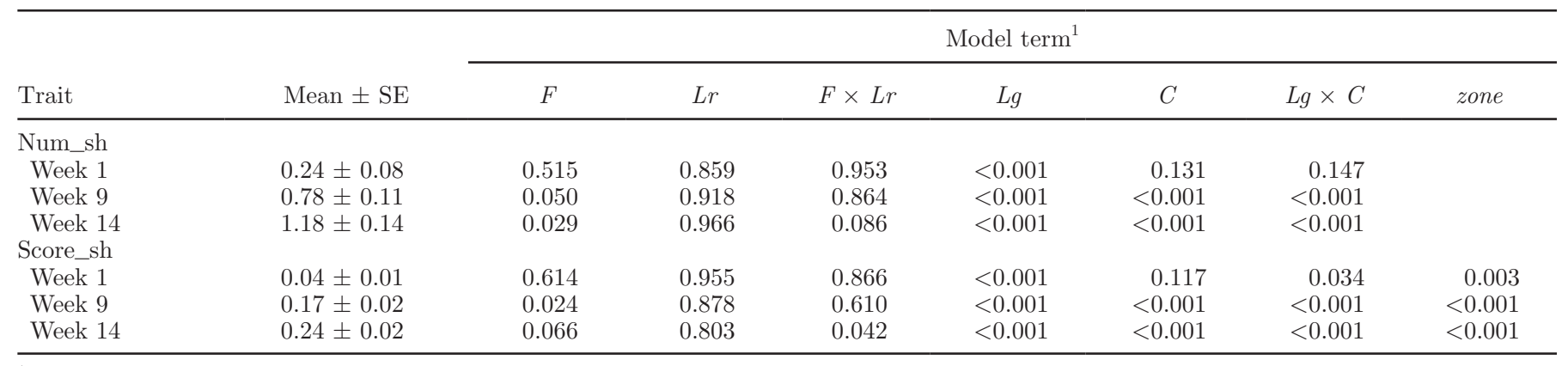

${ }^{1} F=$ flooring, $L r=$ restricted freestall access, $L g=\operatorname{leg}, C=$ claw, and $z o n e=$ area of sole.

because of the low prevalence and severity. In wk 1 score_sh was only slightly higher than num_sh/6, but the difference increased in wk 9 and 14 . This indicates that the hemorrhages initially were usually small and mild, but severity increased during the first $3 \mathrm{mo}$ after calving. Significant differences between zones were found for score_sh throughout the experiment; the predicted means for each zone are presented in Figure 6 . Zones 3, 4, and 6 had significantly more hemorrhages than zones 1,2 , and 5 , particularly 9 and 14 wk after calving. The estimates are dominated by the occurrence of hemorrhages in outer hind claws.

The results for wk 9 and 14 indicate significant effects of flooring, but no effects of restricted freestall access on the occurrence of SH. Generally, the animals kept on the concrete floor had higher scores for num_sh (0.94 \pm 0.14 , wk $9 ; 1.36 \pm 0.16$, wk 14) and score_sh $(0.21 \pm$ 0.03 , wk $9 ; 0.27 \pm 0.03$, wk 14) than the animals kept on the rubber floor $(0.61 \pm 0.14$, wk $9 ; 1.01 \pm 0.16$, wk $14 ; 0.13 \pm 0.03$, wk $9 ; 0.20 \pm 0.03$, wk 14), respectively. In wk 14, the animals with no overnight freestall access on the concrete floor had higher scores $(P<0.05)$ for score_sh than the animals in the other treatment groups $(0.31 \pm 0.04)$, whereas those on the rubber floor had the lowest scores $(0.17 \pm 0.04)$. Therefore, the ef-

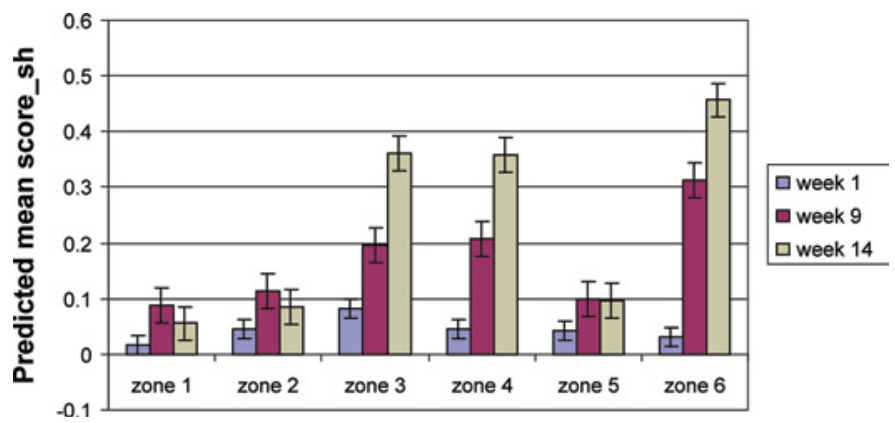

Figure 6. Predicted means $( \pm \mathrm{SE})$ per observation for each claw zone for hemorrhage score per zone. Color version available in the online PDF. fect of floor was not significant, but the interaction of floor and lying restriction was.

\section{Locomotion, BW, and Milk Yield}

Locomotion variables did not differ for the treatment groups; overall predicted means were $1.7 \pm 0.1$ for locomotion score, $8.6 \pm 0.2 \mathrm{~s}$ for duration, and $15.9 \pm$ 0.1 steps to travel $10.36 \mathrm{~m}$. Similarly, no significant differences were found between treatment groups in daily milk yield during the treatment and posttreatment periods. The milk yield was $30.4 \pm 0.6 \mathrm{~kg} / \mathrm{d}$ during the treatment period and $32.5 \pm 0.6 \mathrm{~kg} / \mathrm{d}$ during the posttreatment period. Body weight and patterns of BW change were not significantly different between treatment groups. On average, BW declined from $554 \pm 8$ $\mathrm{kg} 1 \mathrm{~d}$ after calving to $527 \pm 8 \mathrm{~kg} 25 \mathrm{~d}$ after calving, and from then on, gradually increased to $560 \pm 9 \mathrm{~kg} 3$ mo after calving.

\section{DISCUSSION}

The aim was to quantify effects of housing conditions that presumably differ in mechanical load and thus might affect the prevalence of SH. The results support the hypothesis that compliant rubber-topped floors decrease the occurrence of SH compared with hard concrete floors, probably because of a reduction in mechanical load, in particular, mechanical stresses. Restricted freestall access resulted in longer standing bouts and increased activity, but did not result in a significant increase in hemorrhages, and presumably overall mechanical load was only slightly affected. The animals adapted to their circumstances by additional lying time during the rest of the day, such that overall lying time was not significantly affected. Tucker et al. (2006) reported increased occurrence of lying on rubber-topped alley floors compared with concrete alley floors when lying comfort in the freestalls was insufficient. In our study, lying on the alley floor occurred only occasion- 
ally while freestalls were inaccessible, and the similarity of diurnal patterns for animals on concrete floors with restricted freestall access and those on rubber-topped floor with restricted freestall access in Figure 4 indicates that this did not differ between the floor types. We found no cumulative negative effects of repeated periods of lying deprivation on animal well-being as was expected by Cooper et al. (2007), presumably because the animals in our experiment recovered their lying time lost overnight during the next day. Daily feed intakes were not affected by treatments, but animals on hard floors had higher intake speed and shorter meal durations. Figure 5 shows that diurnal variation in feed intake corresponds with patterns for number of standing bouts. Animals without overnight access to the freestalls spent part of the additional nightly standing time feeding. The animals spent around $3 \mathrm{~h} / \mathrm{d}$ on PMR intake. Productive performance and BW change were not affected significantly by treatments.

Heifers were chosen as experimental animals because they presumably are relatively susceptible to hemorrhages and have minimal history regarding claw disorders. Information on the claw health of heifers before first calving is scarce, but Frankena et al. (1992) suggested that they may already have lower claw health at the time of first calving. The scores for claw disorders in the first week after calving indicated that apart from some small hemorrhages, the animals had good claw health after calving. We assume that keeping them in a straw pen the last $5 \mathrm{wk}$ before calving was beneficial for their claws. Because of the low claw disorder prevalence when the animals entered the experiment, the 3 periods were analyzed separately. Additional analyses showed that analyzing the incidence of SH posttreatment (i.e., taking only claws into account that did not show $\mathrm{SH}$ during the first observation) gave almost identical results.

Both restricted freestall access and hard concrete floors were expected to increase mechanical load and thus would be risk factors for SH occurrence. The lower prevalence of $\mathrm{SH}$ on rubber floors found in this study indicated beneficial effects of compliant flooring on claw health, even though the effects of rubber flooring were probably underestimated. A substantial portion of activity took place around milking, when all animals walked on the same concrete slatted floor, whereas peak loads during walking are higher than those during standing. Moreover, this exposure to concrete flooring could have diminished beneficial effects of soft flooring on the maintenance of sole concavity that were reported by Telezhenko (2007). In contrast to results reported by Kremer et al. (2007) and Ouweltjes et al. (2009), more standing or higher activity was not found on the rubber floor. This may be due in part to differences in conditions. The pens where the animals were kept were rather compact; the animals only had to cross the alley to go from the freestalls to the feeders. Despite this, the cows in Ouweltjes et al. (2009) had lower percentages of standing (50 to 55\%) and fewer strides per hour (53 to 61 ) than the heifers in this study, particularly during the treatment period. In the current study, heifers were milked twice daily in a conventional parlor and were monitored in the first 3 mo after calving, whereas in the earlier studies older cows were milked with automated milking systems and were monitored not solely in early lactation.

During the experimental period, the prevalence and severity of SH clearly increased, particularly in zones 3 , 4 , and 6 . This largely supports the patterns for pressure distribution reported by Van der Tol et al. (2002). The increase in SH occurrence after calving supports the results of Leach et al. (1997) and Webster (2002), who reported peak prevalence of hemorrhages within 3 mo after calving. In contrast, Sogstad and Østerås (2005b) observed a peak in hemorrhage occurrence around 5 to 7 mo after calving. Therefore, our observations could have missed the effects of the treatments on claw health that would become visible beyond 3 mo after calving. No remaining effects of the treatments were found during the posttreatment period for behavioral variables, milk yield, BW, and feed consumption. Furthermore, peaks of standing time and activity occurred around calving and time budgets for lying and standing, and activity levels were stable at the end of the posttreatment period. Therefore, it is unlikely that continued recording would have shown additional effects of the treatments.

Because Kremer et al. (2007) and Ouweltjes et al. (2009) reported more standing and higher activity for cows kept in stalls with rubber alley floors instead of concrete floors, it was suggested that flooring might affect feed intake. Despite the absence of effects of flooring on the percentage of time spent standing and activity, the animals on the rubber alley floor in our study indeed spent more time feeding, but at a lower rate. This did not result in an increased feed intake. Restricted freestall access affected diurnal feed intake patterns, but did not affect overall feed intake. Similarly, effects of the treatments on locomotion, BW change, and milk yield were not significant. For restricted freestall access, this corresponded with the absence of detectable effects on claw health and feed intake. Apparently, the lower number of hemorrhages of the animals on the rubber floor did not significantly affect their locomotion or performance. In contrast, Telezhenko (2007) reported improved locomotion for cows on rubber flooring, but we scored locomotion when the animals walked on a concrete slatted floor and not on the alley floors in 
their treatment environment. Moreover, contrasts between concrete and rubber flooring groups in our study might have been reduced because the alleys between the treatment compartments and the parlor, which the animals crossed twice daily, had concrete slatted floors.

\section{CONCLUSIONS}

The heifers showed increased activity and increased standing around parturition. The results confirm the hypothesis that hard concrete flooring causes claw hemorrhages induced by high mechanical load. The hypothesis that restricted freestall access reinforces effects of hard flooring on claws through prolonged standing bouts is rejected for the circumstances of the study. The applied restrictions on freestall access may not be representative for lying restrictions under practical circumstances. Heifers kept on hard flooring spend less time feeding than heifers kept on soft rubber flooring, but other behavioral differences that could be related to flooring were not detected. Neither flooring nor restricted freestall access affected feed intake level, milk yield, or BW changes.

\section{ACKNOWLEDGMENTS}

The support of the Waiboerhoeve research farm staff (especially M. de Bree, H. Bakker, and A. Mooiweer; Wageningen UR Livestock Research, Lelystad, the Netherlands) is appreciated, and we are indebted to M. Janssen and L. Nootenboom (Hogeschool InHolland, Delft, the Netherlands) for their assistance with data collection. R. Zom (Wageningen UR Livestock Research, Lelystad, the Netherlands) took care of ration formulation. The work was funded by the Dutch Ministry of Agriculture, Nature and Food Quality (LNV), research program Animal Welfare (KB-08-001-006).

\section{REFERENCES}

McNeill Alexander, R. 2003. Principles of Animal Locomotion. Princeton University Press, Princeton, NJ.

Cook, N. B., and K. V. Nordlund. 2009. The influence of the environment on dairy cow behavior, claw health and herd lameness dynamics. Vet. J. 179:360-369.

Cooper, M. D., D. R. Arney, and C. J. C. Phillips. 2007. Two- or fourhour lying deprivation on the behavior of lactating dairy cows. J. Dairy Sci. 90:1149-1158.

Donovan, G. A., C. A. Risco, G. M. DeChant Temple, T. Q. Tran, and H. H. van Horn. 2004. Influence of transition diets on occurrence of subclinical laminitis in Holstein dairy cows. J. Dairy Sci. $87: 73-84$.

Flower, F. C., A. M. de Passillé, D. M. Weary, D. J. Sanderson, and J. Rushen. 2007. Softer, higher friction flooring improves gait of cows with and without sole ulcers. J. Dairy Sci. 90:1235-1242.

Frankena, K., K. A. S. van Keulen, J. P. Noordhuizen, E. N. Noordhuizen-Stassen, J. Gundelach, D. J. de Jong, and I. Saedt. 1992. A cross-sectional study into prevalence and risk indicators of digital haemorrhages in female dairy calves. Prev. Vet. Med. 14:1-12.

Galindo, F., D. M. Broom, and P. G. G. Jackson. 2000. A note on possible link between behaviour and the occurrence of lameness in dairy cows. Appl. Anim. Behav. Sci. 67:335-341.

Holzhauer, M. 2006. Claw health in dairy cows in the Netherlands. Epidemiological aspects of different claw disorders in dairy cattle in the Netherlands. PhD Thesis. Universiteit Utrecht, the Netherlands.

Kremer, P. V., S. Nueske, A. M. Scholz, and M. Foerster. 2007. Comparison of claw health and milk yield in dairy cows on elastic or concrete flooring. J. Dairy Sci. 90:4603-4611.

Leach, K. A., D. N. Logue, S. A. Kempson, J. E. Offer, H. E. Ternent, and J. M. Randall. 1997. Claw lesions in dairy cattle: Development of sole and white line haemorrhages during the first lactation. Vet. J. $154: 215-225$.

Leach, K. A., D. N. Logue, J. M. Randall, and S. A. Kempson. 1998. Claw lesions in dairy cattle: Methods for assessment of sole and white line lesions. Vet. J. 155:91-102.

Le Fevre, A. M., D. N. Logue, J. E. Offer, I. McKendrick, and G. Gettinby. 2001. Correlations of measurements of subclinical claw horn lesions in dairy cattle. Vet. Rec. 148:135-138.

Leonard, F. C., J. M. O'Connell, and K. J. O'Farrell. 1996. Effect of overcrowding on claw health in first calved Frisian heifers. Vet. J. $152: 459-472$

Logue, D. N., J. E. Offer, and R. D. McGovern. 2004. The bovine digital cushion-How crucial is it to contusions on the bearing surface of the claw of the cow? Vet. J. 167:220-221.

Manson, F. J., and J. D. Leaver. 1988. The influence of concentrate amount on locomotion and clinical lameness in dairy cattle. Anim. Prod. 47:185-190.

Ouweltjes, W., M. Holzhauer, P. P. J. van der Tol, and J. van der Werf. 2009. Effects of two trimming methods of dairy cattle on concrete or rubber-covered slatted floors. J. Dairy Sci. 92:960-971.

Rushen, J., and A. M. de Passillé. 2006. Effects of roughness and compressibility of flooring on cow locomotion. J. Dairy Sci. 89:29652972.

Sogstad, Å. M., T. Fjeldaas, O. Østerås, and K. Plym Forshell. 2005a. Prevalence of claw lesions in Norwegian dairy cattle housed in tie stalls and freestalls. Prev. Vet. Med. 70:191-209.

Sogstad, Å. M., and O. Østerås. 2005b. Lameness and claw lesions of the Norwegian red dairy cattle housed in freestalls in relation to environment, parity and stage of lactation. Acta Vet. Scand. 46:203-217.

Somers, J. G. C. J. 2004. Claw disorders and disturbed locomotion in dairy cows: The effect of floor systems and implications for animal welfare. $\mathrm{PhD}$ Thesis. Universiteit Utrecht, the Netherlands.

Tarlton, J. F., D. E. Holah, K. M. Evans, S. Jones, G. R. Pearson, and A. J. F. Webster. 2002. Biomechanical and histopathological changes in the support structures of bovine hooves around the time of first calving. Vet. J. 163:196-204.

Telezhenko, E. 2007. Effect of flooring system on locomotion comfort in dairy cows: Aspects of gait, preference and claw condition. $\mathrm{PhD}$ Thesis. Swedish University of Agricultural Sciences, Skara, Sweden.

Tucker, C. B., D. M. Weary, A. M. de Passillé, B. Campbell, and J. Rushen. 2006. Flooring in front of the feed bunk affects feeding behavior and use of freestalls by dairy cows. J. Dairy Sci. 89:2065-2071.

Van der Tol, P. P. J., J. H. M. Metz, E. N. Noordhuizen-Stassen, W. Back, C. R. Braam, and W. A. Weijs. 2002. The pressure distribution under the bovine claw during square standing on a flat substrate. J. Dairy Sci. 85:1476-1481.

Vanegas, J., M. Overton, S. L. Berry, and W. M. Sischo. 2006. Effect of rubber flooring on claw health in lactating dairy cows housed in freestall barns. J. Dairy Sci. 89:4251-4258.

Webster, A. J. F. 2002. Effects of housing practices on the development of foot lesions in dairy heifers in early lactation. Vet. Rec. 151:9-12. 